\title{
Wear behavior of chromium nitride coating in dry condition at lower sliding velocity and load
}

\author{
Shailesh Kumar Singh ${ }^{1} \&$ Somnath Chattopadhyaya ${ }^{1} \&{\text { Alokesh } \text { Pramanik }^{2} \text { \& Sanjeev Kumar }}^{3}$ \\ ${ }^{1}$ Department of Mechanical engineering, Indian Institute of Technology (ISM), Sardar Patel Nagar, \\ Dhanbad, Jharkhand 826004, India \\ ${ }^{2}$ Department of Mechanical engineering, Curtin University, Bentley, WA 6102, Australia \\ ${ }^{3}$ Department of Mechanical engineering, Krishna Engineering College, Ghaziabad 201007, India
}

\begin{abstract}
The wear behavior of the chromium nitride $(\mathrm{CrN})$ coating on piston ring material against liner material was investigated under dry conditions at room temperatures. Cat iron alloy, widely used in manufacturing of piston rings and cylinder liners, further it was coated by physical vapour deposition method. Wear tests were carried out on a Pin on Disc tribometer, Simultaneous effect of sliding velocities $(0.3,0.4,0.6 \& 0.8 \mathrm{~m} / \mathrm{s})$ and corresponding loads $(10,20,30 \& 40 \mathrm{~N})$ on wear rate, friction coefficient and temperature were analyzed. In conclusion, Specific wear rate is decreasing by increase in load and velocity. The rise of temperature is $28^{\circ} \mathrm{C}$ to $42^{\circ} \mathrm{C}$ at the wear track room temperature resulted in a reduced coefficient of friction $(\mathrm{COF})$ when the increase of load from10 to 40N.The wear mechanism is mixed mode such as three body abrasion and oxidation wear for dry conditions.
\end{abstract}

Key-Words: Physical vapour deposition (PVD), Chromium Nitride (CrN), Wear, COF, Effect of Temperature

\subsection{Introduction}

Tribological performance of piston-ring and cylinder liner combination in an internal combustion engine has been recognized as considerable factor in engine efficiency and durability in terms of various aspects like fuel consumption, power loss, oil consumption, and even harmful exhaust emissions [1].Internal combustion engine used many considerable components in the combustion chamber. If the tribological features of pistons-cylinder and ring-liner are improved, energy 
consumed by friction will definitely decrease, and overall emission and performance values will improve. The improvement of wear resistant properties of a cast iron piston ring-cylinder liner pair of an internal-combustion engine can exert an important influence on maintaining service properties, extending service life and reducing the repair costs. Various ceramic materials are also used in coating to improve features of this material with lower weight and volume. Piston and cylinder materials are light alloys, cast iron, nodular cast iron, and alloyed steels. The pistons for high speed engines are primarily made of aluminum silicon alloys [2-3]. One of available hard coating materials $\mathrm{CrN}$, which has attracted attention due to its characteristic high resistance to wear with a thin film coating. Chromium nitride coating $(\mathrm{CrN})$ are commonly used in decorative and wear film applications because of their exceptional mechanical property. CrN film necessity of severe environment, such as when $\mathrm{CrN}$ protective coatings are deposited on integrated circuit packaging molding dies. Coating failure of $\mathrm{CrN}$ in working temperatures is around $200-300{ }^{\circ} \mathrm{C}$ when used in automotive components [4]. Strength plays a major role in the wear behavior of automobile components due to structural characteristics, excessive surface roughness and inadequate strength. Thus, increase the life of pistons cylinder assembly will both grow longer life of the engine and contribute to the economy of the engine. Recently, CrN coatings have concerned more attentions because of their some unavoidable mechanical properties like high hardness and very good wear resistance, chemical inertness and low internal stresses as well as the superior oxidation resistance up to $700^{\circ} \mathrm{C}$. Another well-known benefit is to reduce the environmental pollution by replacing the hard chromium by 20 to $30 \mu \mathrm{m} \mathrm{CrN}$ coating for reducing the friction and wear of piston rings. Generally, $\mathrm{CrN}$ coatings are formed by arc or sputtering technique and of which the deposition rate is very low [5-10]. It will need about 8-10 h to produce 20-30 $\mu \mathrm{m}$ thick $\mathrm{CrN}$ coatings which increase costs of mass production. However, the distribution of wear throughout the sliding contact, or the evolution during the sliding experiment remains unknown. In this study, piston ring material of an internal combustion engine was coated with $\mathrm{CrN}$ by using the arc PVD method. The purpose of this study is to analyze mild wear or tribological effects of surface coating at low sliding velocity and load for piston rings in frictional mechanism.

\section{Material and method}

2.1 Physical vapour deposition (PVD) 
Advanced coating technologies like thermal spray processes, physical vapor deposition (PVD) and diffusion coating processes are commonly used in the automotive engineering [11]. PVD process is an atomistic deposition method that involves the vaporization and subsequent deposition of coating material which has the advantage to deposit metals, alloys and ceramics on most materials and a wide range of shapes. To achieve the desired columnar ceramic coating structure, the parts must be preheated to a certain temperature. Development of the fabrication technique, process parameters it's limits, and monitoring/control techniques to give a good quality component. The surface of sample were structured by means of micro-milling machine.PVD device was used to deposit the coating system. Specimen was heated up to a temperature of $450^{\circ}$ approximately during the coating process. Vacuum chamber mainly consist of nitrogen as a carrier gas and acetylene with the argon in rest condition at a pressure of 550Mpa. Chromium cathodes were powdered with 2600-2800 W and a pulse frequency was adjusted and the temperature of the chamber increases and at a particular temperature around $1536^{\circ} \mathrm{c}$ nitrogen gets converted to its nitride phase. The coating of $12.3 \mu \mathrm{m}$ thick had $92.23 \%$ chromium and $7.77 \%$ nitrogen which was composed of small grains and embedded in a dense structure throughout the film.

Table1Composition of cast iron alloy piston rings

\begin{tabular}{|l|c|c|c|c|c|c|c|c|c|c|}
\hline Element & $\mathrm{Fe}$ & $\mathrm{C}$ & $\mathrm{Si}$ & $\mathrm{Mn}$ & $\mathrm{Cr}$ & $\mathrm{W}$ & $\mathrm{V}$ & $\mathrm{Ti}$ & $\mathrm{P}$ & $\mathrm{S}$ \\
\hline Content & $91-$ & $3.4-$ & $2.4-$ & $0.6-$ & $0.2-$ & $0.15-$ & $0.15-$ & 0.05 & $0.25-$ & 0.1 \\
$(\%)$ & 93 & 4 & 3.0 & 1 & 0.4 & 0.16 & 0.25 & & 0.45 & \\
\hline
\end{tabular}

\subsection{Pin on Disc Test}

Pin on disc tribometer with data acquisition system was used to evaluate the wear behavior of coated material on the disc under dry condition. Load was applied on the pin by the dead weight through pulley string arrangement as shown in Fig-1. The system had maximum loading capacity of $200 \mathrm{~N}$. The rate of wear is evaluated by weighing the disc before and after the wearing in grams (g) and the least count of the electronic weight balance used is $0.00001 \mathrm{~g}$. The experiments were performed at $20^{\circ} \mathrm{C}$ by varying load and speed according to the table-2. The pin was cleaned after each run to have direct contact with the disc as debris were deposited on the pin during experiments.

Table-2 Experimentation details 


\begin{tabular}{|c|c|c|c|c|c|}
\hline $\begin{array}{c}\text { Sliding Velocity } \\
(\mathbf{m} / \mathbf{s})\end{array}$ & $\begin{array}{c}\text { Speed } \\
(\mathbf{R p m})\end{array}$ & $\begin{array}{c}\text { Time of Run for each track } \\
\text { (Seconds) }\end{array}$ & $\begin{array}{c}\text { Sliding distance } \\
(\mathbf{M e t e r})\end{array}$ & $\begin{array}{c}\text { Load } \\
(\mathbf{N})\end{array}$ & $\begin{array}{c}\text { Track Diameter } \\
(\mathbf{m m})\end{array}$ \\
\hline $0.3 \quad($ Track-1) & 96 & 3317 & 1000 & 10 & 60 \\
\hline $0.4 \quad($ Track-2) & 153 & 2497 & 1000 & 20 & 50 \\
\hline $0.6 \quad($ Track-3) & 287 & 1666 & 1000 & 30 & 40 \\
\hline $0.8 \quad($ Track-4) & 510 & 1250 & 1000 & 40 & 30 \\
\hline
\end{tabular}

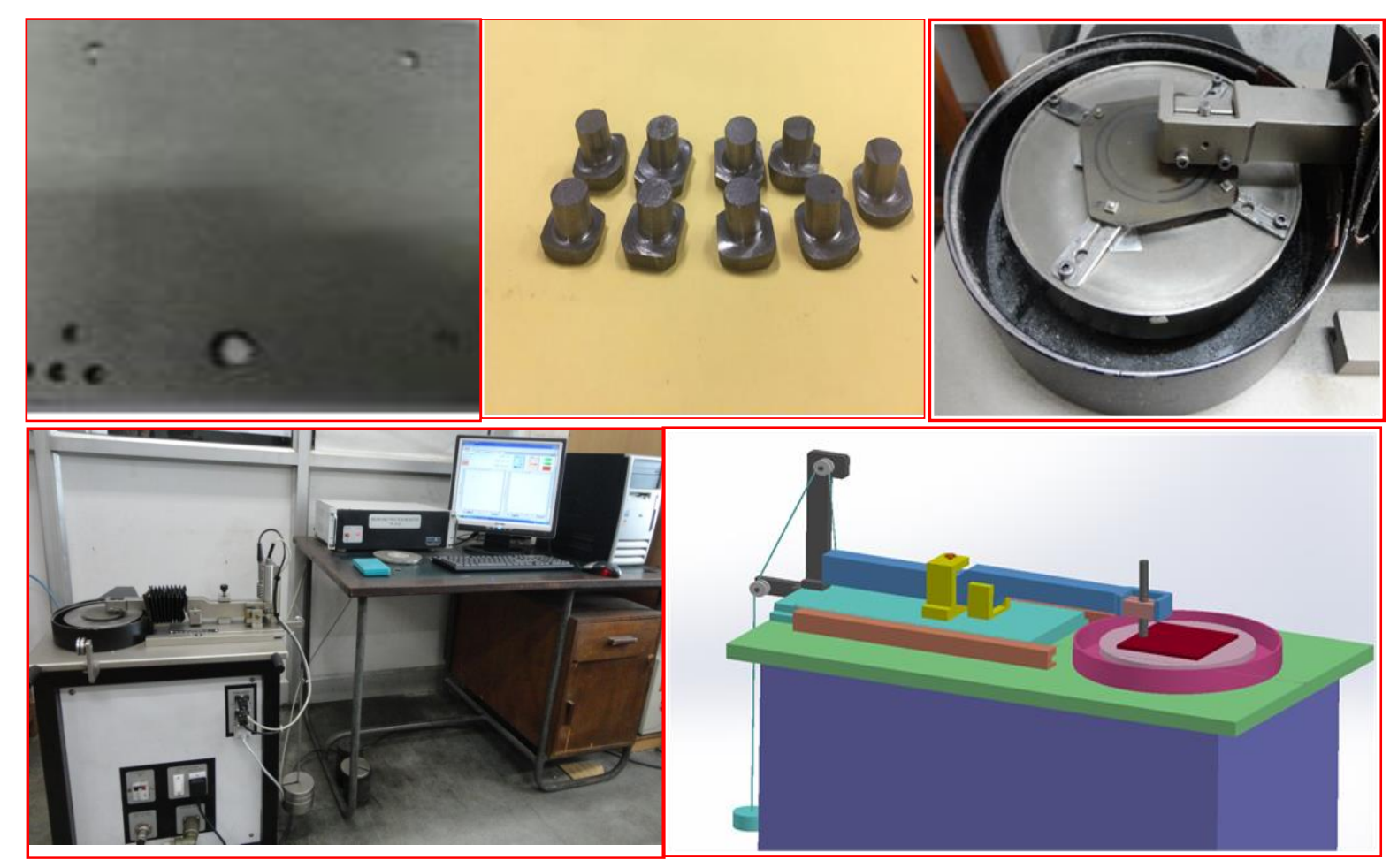

Figure-1 (a) coated sample (b) Counter body of cylinder liner material (c) Pin-On Disc Tribometer Set-Up(d) CAD Model of Pin-On Disc Tribometer

The temperature generated at pin on Disc tribometer is recorded by thermal Imaging Camera at four successive track at sliding velocities $0.3,0.4,0.6$ and $0.8 \mathrm{~m} / \mathrm{s}$, and corresponding loads 10, 20, 30 and 40N.The standard way of measuring wear of materials during the past decades of tribolology is by investigative the difference in the material or samples before and after the experiment at tribometer, through weighing, mechanical gauging and/or optical inspection. Weighing is probably the easiest way of examining wear and used in the current study also. An important aspect of the weighting method is the cleaning procedure, which determines to a considerable extend, the accuracy of the measurement [12].

\section{Result and discussion}




\subsection{Specific Wear Rate}

A wear coefficient is often used to categories resistance to contact wear. It is used to calculate the specific wear rate or wear coefficient $(\mathrm{K})$ by the expression below.

$$
K=\frac{\text { Wear Volume }}{\text { Load } * \text { Sliding distance }}
$$

Where wear volume is in $\mathrm{mm}^{3}$ and load is in Newton and sliding distance is in meter. Above wear coefficient was suggested by Holmberg and Matthews as a standard for wear test [13].Similar to the frictional force, these wear coefficient or quantities should be considered as system dependent, depending on (i) materials in contact, (ii) surrounding and system (iii) operational conditions.

Wear behavior of HVOF for engine components and chromium nitride coating has been studied by (J.A. Picas et.al (2006), Wei Weng et.al. (2008)) and suggest that the formation of hard phases like carbide, nitride and fine microstructure reduce the pullout of hard particles so that they provide less damage to coating because they are less effective as a third-body abrasives. When the inserted strengthened layer and dispersed hardened phases are completely worn away during wear test at tribometer the wear behavior enters another stage, which is controlled by the wear of the CrN film until ultimate failure [14-15]. M.B.Karamıs et.al. (2005) shows the variations of the specific wear rate with test temperature that can be related to the load and sliding velocity and to wear depth measured as the distance from the coating surface. Increasing tendency of the wear coefficients is characteristically similar to the wear depth distribution in the layer with test temperatures under dry condition [16] .M.singh.et.al. (2002) reported the decreasing of specific wear rate with increasing velocity at a constant sliding distance. This may be due to work hardening of wear surface, clogging, attrition and shelling of abrasive particles [17].

The current investigation will give an indication of combined effects of wear coefficient at different sliding velocity and load shown in Figure-2.Our analysis shows that at the start of wear test in first track $(0.3 \mathrm{~m} / \mathrm{s}$ and $10 \mathrm{~N})$ the wear coefficient is very high. The highest specific wear rate (0.0011) is found in all the four conditions. This indication shows that the resistance of wear is very low in the starting of rubbing both the element pin and disc. 
Upon further increasing the sliding velocity and load successively, the pattern of specific wear rate is showing a decreasing trend can be observed in Figure-2.Minimum wear coefficient (function of wear depth) can be observed in fourth track $(0.8 \mathrm{~m} / \mathrm{s}$ and $40 \mathrm{~N})$ is 00000.91 . This is due to the fact as the normal load increases frictional heat generates at the contact surface and hence strength of materials decreases at constant sliding distance.EDS analysis of wear track reveals the oxide layer formation during the sliding of chromium nitride coated disc and liner as a pin material. Three body abrasions (presence of wear debris) confirmed by abrasive and adhesive wear followed by oxidation wear and induce reduction in wear coefficient.

Probably weighing is the easiest way to calculate weight loss (wear). However, the distribution of wear and it's mechanism throughout the sliding contact, or the development during the sliding experiment remains unpredictable. Weighing method is also followed by the cleaning procedure to the disc (CrN coated) and pin (liner material) which determines to a considerable extends the accuracy of the measurement.

During the wear test the maximum weight loss of pin (counter-body) and the coated sample is obtained 0.007 grams \& 0.0029 grams at track-1 $(0.3 \mathrm{~m} / \mathrm{s}$ and $10 \mathrm{~N})$.It is decreasing successively from track-1 to track-4, weight loss of pin $(0.007,0.006,0.0045,0.0041)$ and plate are $(0.0029$, $0.0021,0.0023,0.0015)$ reported in Figure-3. It can be observed that when load and sliding velocity is increasing successively the weight loss is decreasing. The weight loss (wear) of PVD coatings strongly reliant on the $\mathrm{CrN}$ characteristics and it's structure, the chemical interactions and the transfer layer or film formation on the both disc and pin or counter body. The local interface temperature is usually higher than the ambient temperature in which experimentation was done, also because of hot-spots at local asperity contact. These mechanisms and their interaction hamper a precise classification of the wear processes taking place in coating. When the hard particles come loose in the contact, or become entrenched into the counter surface, three-body abrasion takes place. Due to the three body abrasion weight loss of plate in track-2 to track-3 is slightly increasing (0.0021to 0.0023) but the overall effect of weight loss as reported in Figure-3 is decreasing. 


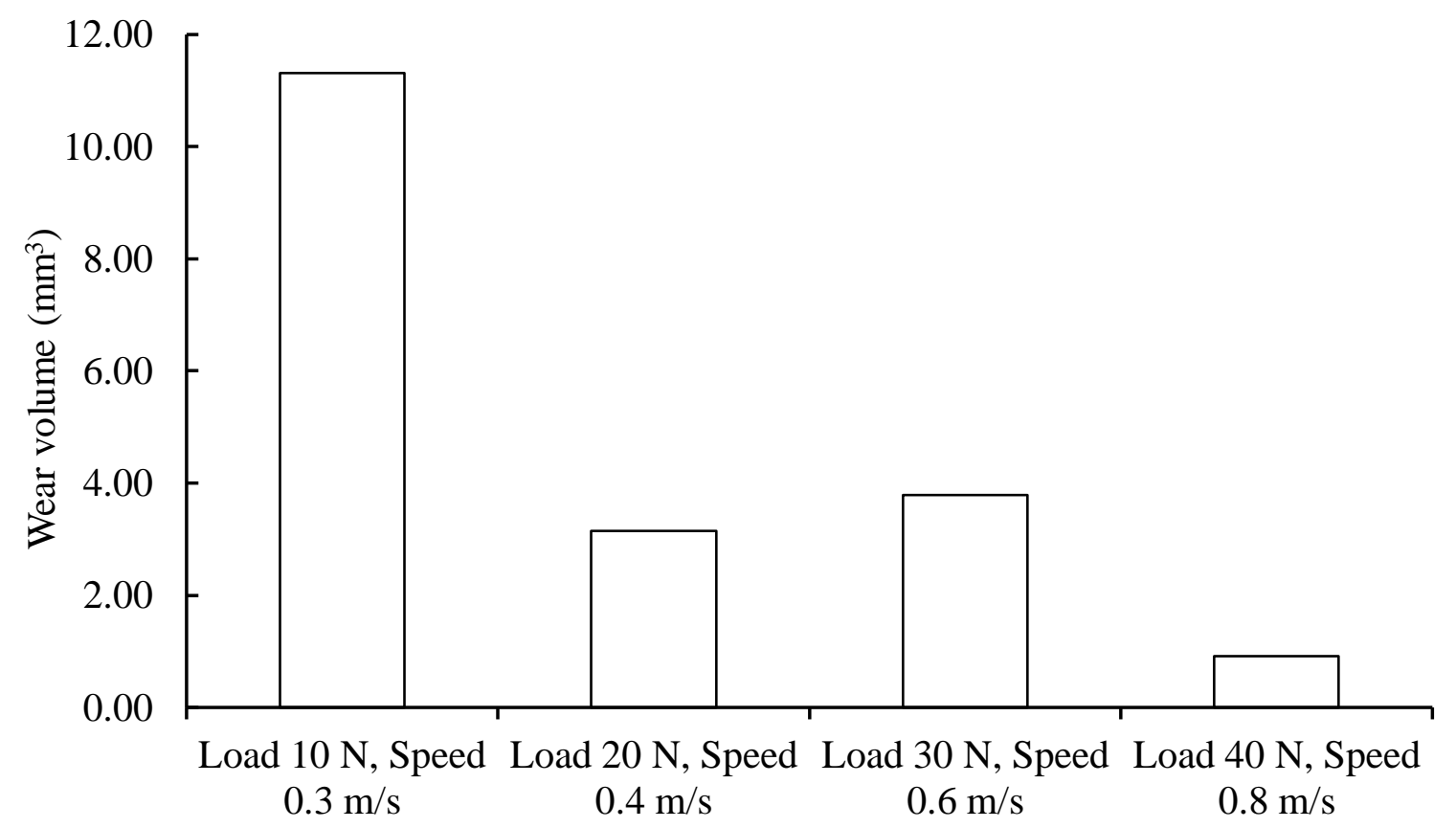

Figure 2 Specific wear rate at different sliding speed and load

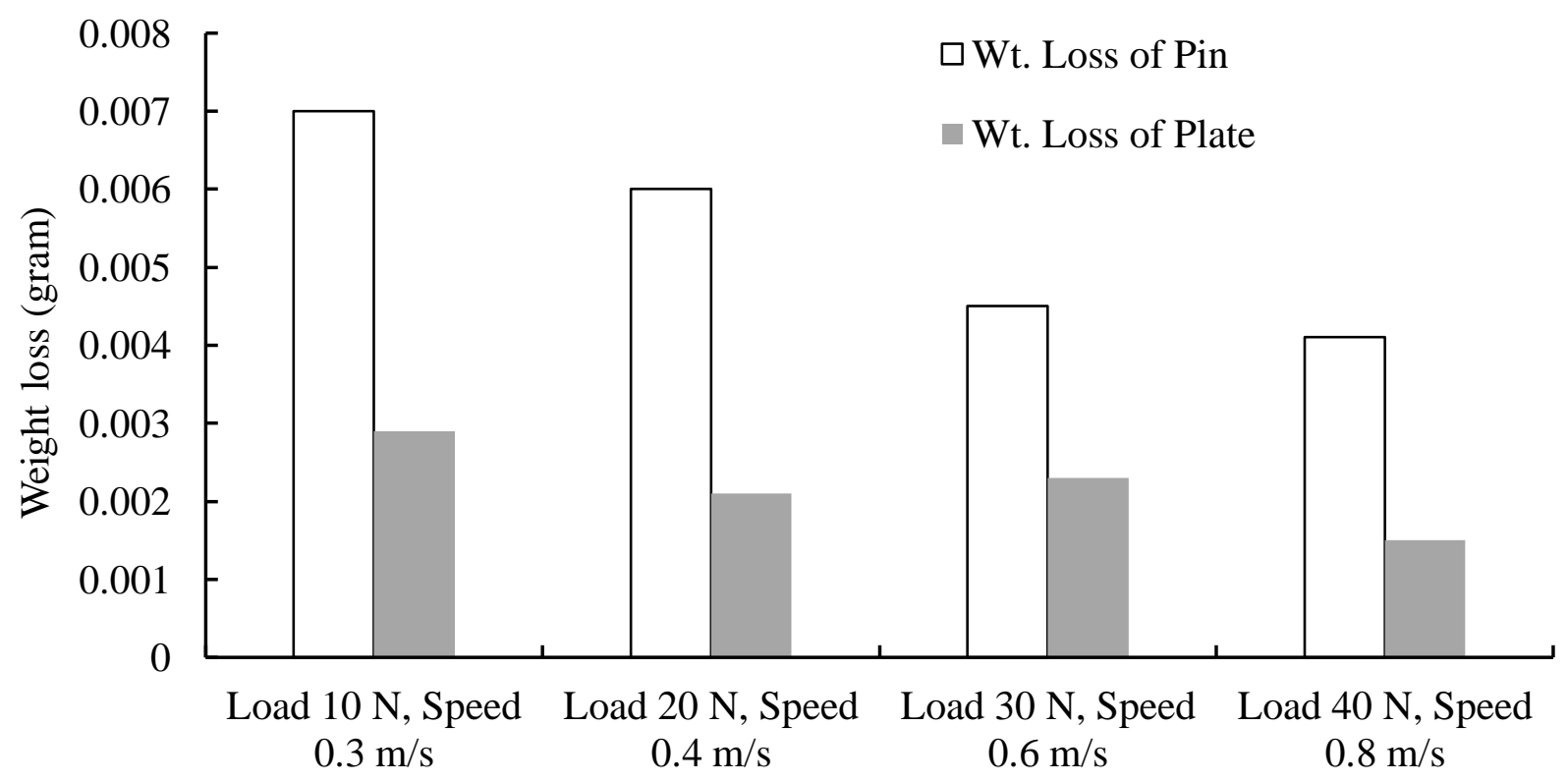

Figure 3 Weight loss of coated sample and counter body at different sliding speed and load. 


\subsection{Coefficient of friction}

Wear behavior of chromium nitride is being characterized by the pin-on-disc Test tribometer where the frictional force of coated plate is analyzed in dry and the coefficient of friction by the given equation $(\mathrm{F}=\mu \mathrm{N})$; Where $\mathrm{F}=$ Frictional force in Newton, $\mu=$ Coefficient of Friction, $\mathrm{N}=$ Normal force that is the applied load in each track or run of the test.

Coating material plays a vital role in the COF and friction force some of them are discussed here, E. Martinez et.al. (2002) studied the two different carbides coating of tantalum and molybdenum. It was found that the tantalum and molybdenum carbide coatings were not as resistant to abrasion as the titanium nitride. However, due to their extremely low friction coefficient values they were considered superior in sliding applications against both steel and alumina [18].

During tests using a nominal load of $10 \mathrm{~N}$, increasing the temperature from room temperature to $42^{\circ} \mathrm{C}$ resulted in a reduction in the COF. However, at the higher load of $20 \mathrm{~N}$, the temperature virtually did not affect the COF. Higher nominal load resulted in lower COF while higher speed resulted in higher COF reported by W.Y.H. Liew et.al (2012) [19]. Frictional behavior of the $(\mathrm{V}, \mathrm{Ti}) \mathrm{N}$ coatings against the steel ball under boundary-lubricated condition at $20 \mathrm{~N}$ load and different temperatures exhibits a friction coefficient of 0.18 at $50^{\circ} \mathrm{C}$, slightly increases to 0.19 at $100^{\circ} \mathrm{C}$. The coating exhibits a steady friction coefficient with the testing time at all the temperature levels reported by J.H. Ouyang et.al (2004) [20] .

The average friction force measured during unlubricated sliding of disc ( $\mathrm{CrN}$ coatings) against pin (cylinder liner) and represented in Figure-4. It is shown that the wear test has been performed at four loading conditions. A relative higher and approximately constant friction force of 10.83 was observed at $0.8 \mathrm{~m} / \mathrm{s}$ and $40 \mathrm{~N}$ load. It strongly decreases to 5.45 with the decrease in velocity of $0.6 \mathrm{~m} / \mathrm{s}$ and $30 \mathrm{~N}$ load. The lowest average friction force is reported 2.09 at track $-1(0.3 \mathrm{~m} / \mathrm{s}$ and $10 \mathrm{~N})$.From the above discussion and figure-4 it is clear that with low normal load, the friction torque stabilizes after the running-in period for the highest normal load ( $\mathrm{W}=40 \mathrm{~N}$ ), the behaviour frictional force remains fluctuating. After the quick peak formation in starting and then a near about straight line with fluctuation of frictional force and by the formation of protective transfer layers on the contacting surfaces of the pin and coated disc. 
Figures-5shows the evolution of coefficient of friction for a constant sliding distance of $1000 \mathrm{~m}$ at various loads $(10,20,30$ and $40 \mathrm{~N})$ and corresponding sliding velocities $(0.3,0.4,0.6$ and $0.8 \mathrm{~m} / \mathrm{s}$ ). The maximum coefficient of friction is obtained at $0.8 \mathrm{~m} / \mathrm{s}$ and $40 \mathrm{~N}$ load is 0.27 . while the minimum COF is 0.15 at $0.3 \mathrm{~m} / \mathrm{s}$ and $20 \mathrm{~N}$. Generally minimum should be at $0.3 \mathrm{~m} / \mathrm{s}$ and $10 \mathrm{~N}$ but it is 0.20 slightly above than minimum COF it may be due to the settle down of some asperities or debris in the disc ( $\mathrm{CrN}$ coating). The layer development and breakdown is, however, a continuous procedure, which can reach an equilibrium in the case of relatively low energy dissipation in the contact (in the case of low normal load), or remain unstable, which seems to happen in the case of the highest normal load, as can be seen in the signal of the averaged friction.

From our discussion to this section COF and friction force is one of the reasons for the low wear volume with this coating. COF of the contact surface increases because the components transferred are caused by adhesion between the two surfaces and settle down there. EDS analysis of wear track confirms the oxygen is very rich on surfaces and the presence of oxygen may cause the formation of the chromium oxide.Fig-5 plots the friction coefficient as a function of the sliding velocity of chromium nitride coating against pin (cylinder liner) in Pin-on-disc tests. It is striking that, in the steady-state friction stage, all the metal carbide layers presented much lower friction coefficients than the titanium nitride.Track- $2(0.4 \mathrm{~m} / \mathrm{s}$ and $20 \mathrm{~N})$ showed an irregular behavior with an increase in the friction coefficient plot decreasing pattern from track- $1(0.3 \mathrm{~m} / \mathrm{s}$ and $10 \mathrm{~N})$. This was probably caused by the exposure of $\mathrm{CrN}$ inside the wear track, on the other hand, showed a low stable friction coefficient value up to the end of the sliding test in track- $4(0.8 \mathrm{~m} / \mathrm{s}$ and $40 \mathrm{~N})$. 


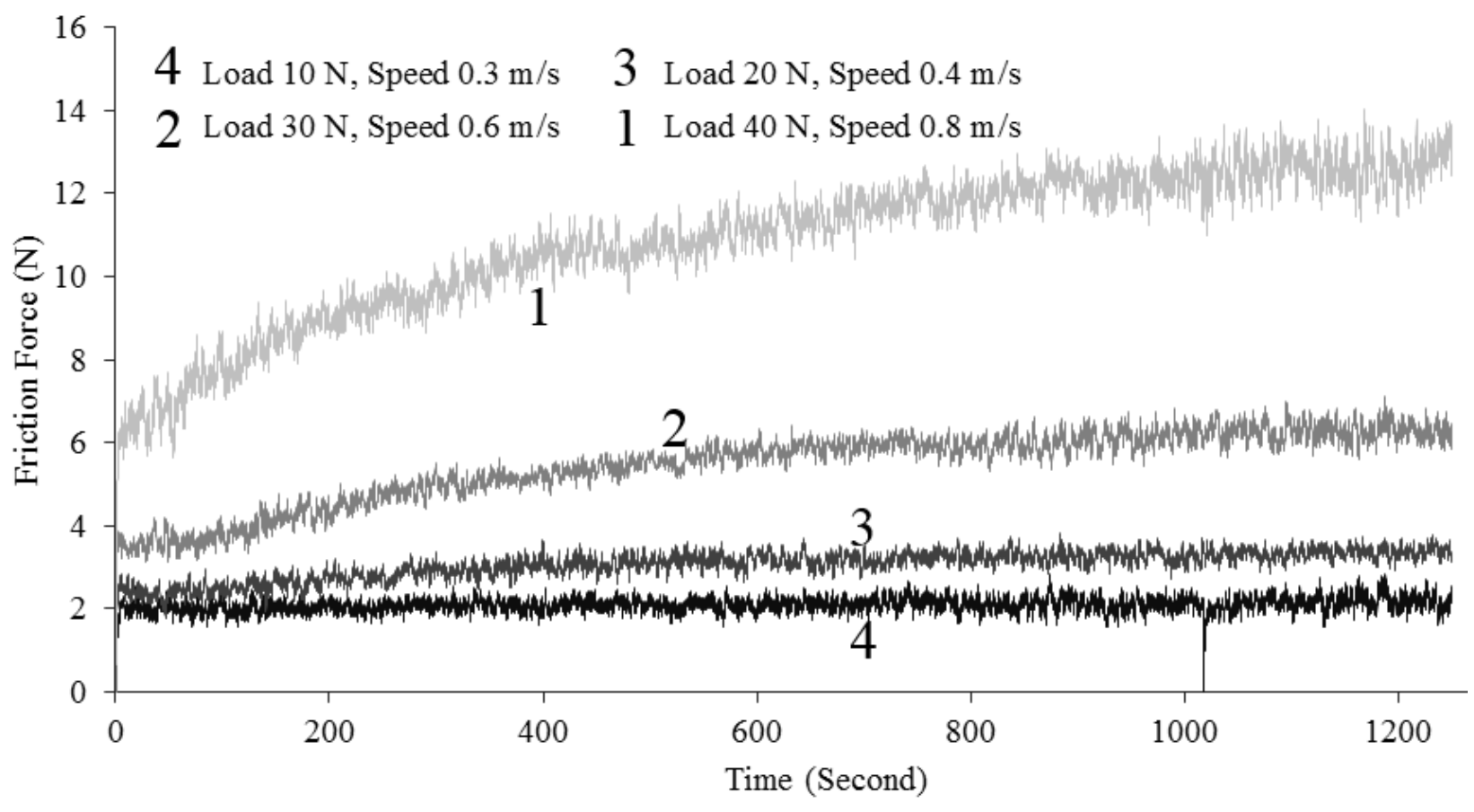

Figure 4 Friction force at low Sliding Velocity with increasing load

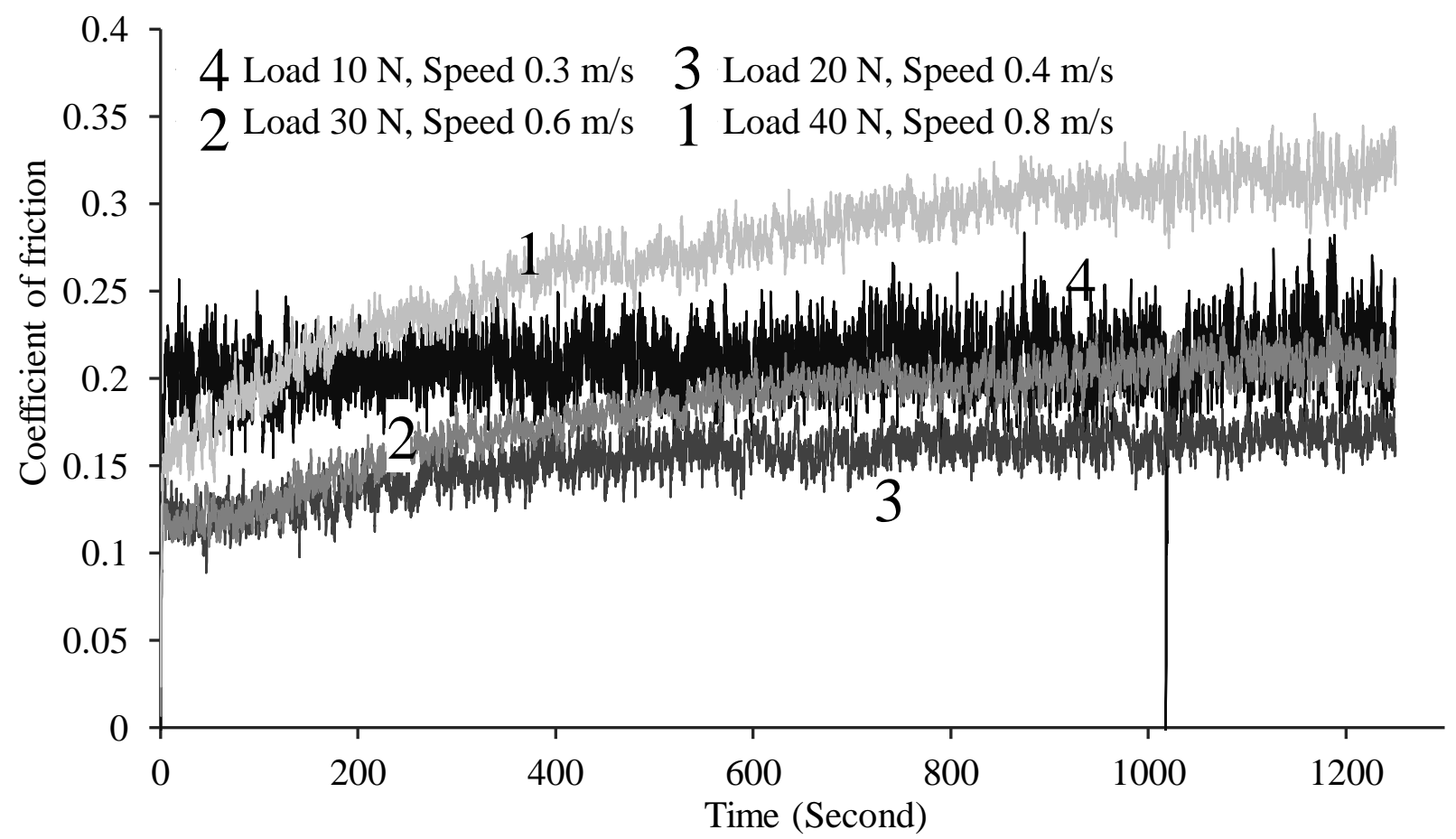

Figure 5 C.O.F. of coated sample 


\subsection{Temperature generation}

In this section, the distribution of temperature at wear track will be discussed. In doing so, a new technique of thermal imaging has been used to record the wear track temperature and plot represented in figure- 6 .

Various researchers also related the temperature and wear, $\mathrm{COF}$ etc. behavior of tungsten carbide coating studied by A. Babilius et.al. (2003) and reported that Increase of the sliding speed from $0.3 \mathrm{~m} / \mathrm{s}$ to $1.5 \mathrm{~m} / \mathrm{s}$ or increase of test temperature from $20{ }^{\circ} \mathrm{C}$ to $600{ }^{\circ} \mathrm{C}$ results decrease of the friction force. It is known that adhesive metal wear rate at elevated temperatures decreases due to the layer of oxides formed on the surface. This phenomenon is known an oxidative wear. According to the model proposed by Jiang.et.at (2001) [21-22]. Many brittle materials show signs of ductile fracture at elevated temperature and brittle fracture at low temperature reported by K.V.Arun et.al. (2008)[23]. Wear decreases at elevated temperatures due to the oxides layer development which results in transport from adhesive wear to oxidative reported by (wear Kim, S.J.et.al (2001) , A. Babilius et.al (2003)) [24-25].

The maximum temperature has been recorded in track- $4(0.8 \mathrm{~m} / \mathrm{s}$ and $40 \mathrm{~N})$ IS $42^{\circ} \mathrm{C}$ that is quite high than the ambient temperature, while the minimum temperature is $28^{\circ} \mathrm{C}$ at $0.3 \mathrm{~m} / \mathrm{s}$ sliding velocity and $10 \mathrm{~N}$ load. When sliding velocity and load is increasing successively form $0.3 \mathrm{~m} / \mathrm{s}$ to $0.4 \mathrm{~m} / \mathrm{s}$ and $10 \mathrm{~N}$ to $20 \mathrm{~N}$ the temperature plot is showing the average temperature is around $31^{\circ} \mathrm{C}$ which is showing a marginal change from track-1. whereas load is increasing from $10 \mathrm{~N}$ to $30 \mathrm{~N}$ there is a considerable change in the maximum temperature is $34^{\circ} \mathrm{C}$ shown if figure-6.The temperature at point of contact affects the coefficient of friction, wear coefficient, friction force of coated sample and also some mechanical properties like fracture toughness because materials property also changes by the variation in temperature.

From our discussion in the previous sections of wear and COF, we can conclude that decrease in specific wear rate (wear coefficient) with the increase in temperature of contact point. This decreased can be explained by increased oxidation of the coating, increased softening and plastic deformation as a result of increase in temperature. It is known that adhesive wear of coating at elevated temperatures decreases due to the layer of oxides formed on the surface and concentrated large particles of wear products fracture into small particles, oxidize, sinter and cover the wear surface. 
Presence of oxygen is confirmed by EDS analysis of wear track. It is done by Energy dispersive spectroscopy (EDS) which is showing that oxygen content is in considerable amount of $14.29 \%$ by weight that is enough to form an oxide layer at surface and causes to occur oxidation wear. Some impurity EDS but that is negligible. While the main constituent's chromium $(54.88 \%$ by weight) and iron (30.05\%) is being confirmed by the peaks of Figure-7 and detailed composition is shown in table-3. If silicon is present in considerable amount it worked as lubrication as reported by some authors discussed below.

Table-4 EDS analysis of wear track of coating

\begin{tabular}{|c|c|c|c|c|c|}
\hline Element & Net Count & Weight\% & Weight\%(Error) & Atom\% & Atom\%(Error) \\
\hline Oxygen & 2384 & 14.29 & \pm 0.55 & 35.55 & \pm 1.36 \\
\hline Silicon & 141 & 0.69 & \pm 0.13 & 0.98 & \pm 0.19 \\
\hline Chromium & 3467 & 54.88 & \pm 1.58 & 42.02 & \pm 1.21 \\
\hline Iron & 1194 & 30.05 & \pm 1.36 & 21.42 & \pm 0.97 \\
\hline Molybdenum & 12 & 0.09 & \pm 0.32 & 0.04 & \pm 0.13 \\
\hline Total & & 100.0 & & & \\
\hline
\end{tabular}

Some other hard coatings are also investigated by various researchers. Zhiqiang Liu et. al. (1999) studied wear mechanism and transition of molybdenum (Mo) coating against bearing steel and concluded that Mo coating were showing 2 to 18 times better than that of uncoated hardened steel [57]. To enhance the tribological properties and coating durability by doping of silicon ( $\mathrm{Si}$ ) this in turn can affect hardness and improves the adhesion of coating by lowering the internal stress. Doping also help to form a protective layer composed of recognized wear reducing element like sulphur, phosphorus, calcium and zinc reported by Lanigan et. al. (2015) [26-27]. 


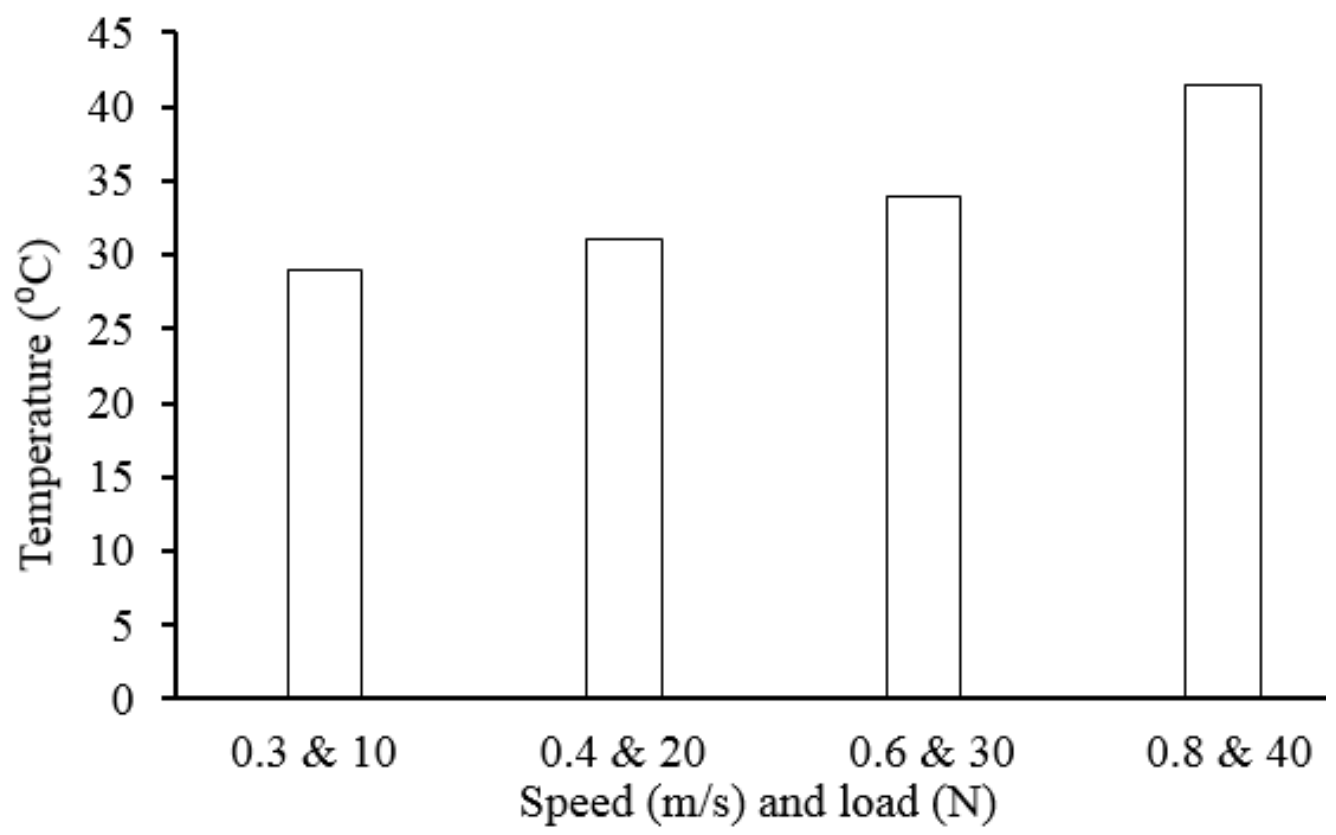

Figure 6 Temperature generation with increasing load and sliding velocity

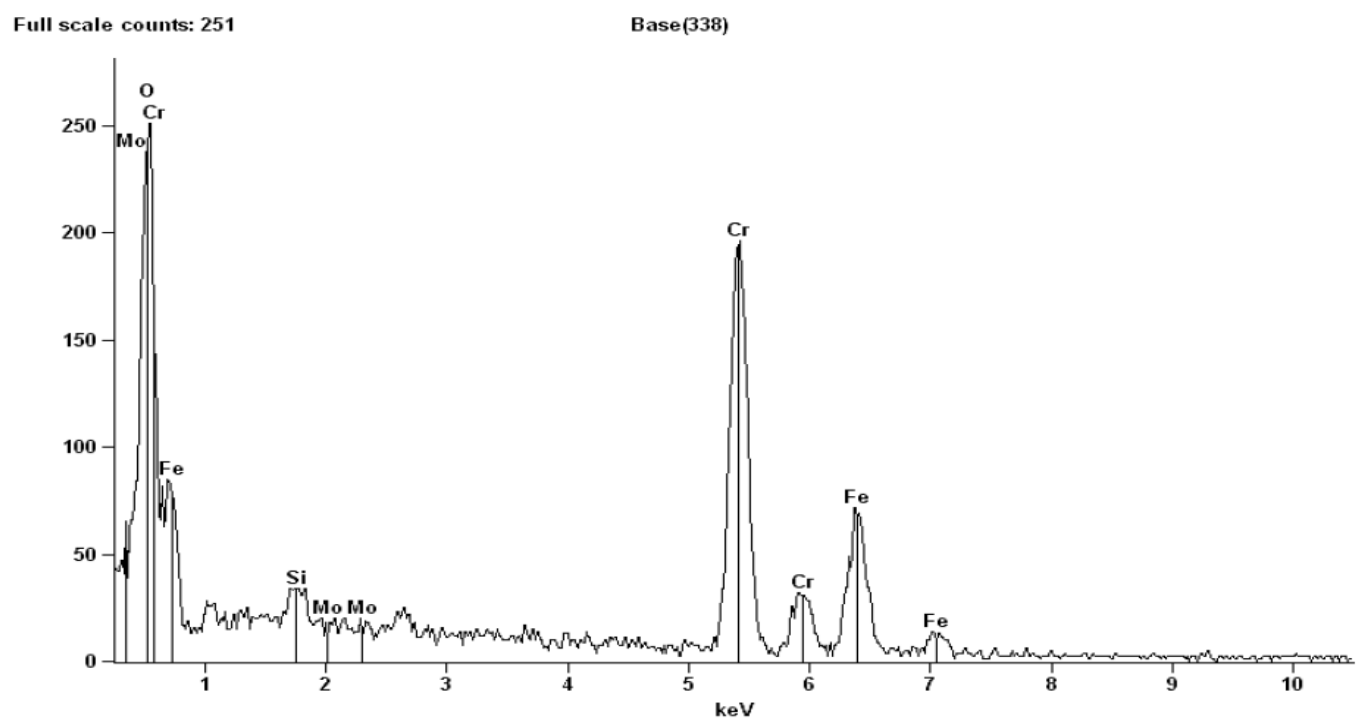

Figure 7 EDS analysis of wear track 


\section{Conclusion}

The chromium nitride was coated by PVD at the cast iron of same as piston ring materials shown in table-1.wear test is performed at Pin on Disc tribometer, coated sample was as a disc and cylinder liner material as a counter body.

The current study has demonstrated the deposition of coating surface with good adhesion on substrates and the coating thickness is around $13 \mu \mathrm{m}$. The wear tests at different load (10N to $40 \mathrm{~N})$ and sliding velocity $(0.3 \mathrm{~m} / \mathrm{s}$ to $0.8 \mathrm{~m} / \mathrm{s})$ have performed and calculated the specific wear rate. Specific wear rate is decreasing by increase the load and sliding velocity successively. This is due to the fact as the normal load increases frictional heat generates due to rising of temperature from $28^{\circ} \mathrm{C}$ to $42^{\circ} \mathrm{C}$ to the contact surface and hence strength of materials decreases and may also be due to the fact that hardening of wear surface, clogging, attrition and shelling of abrasive particles. Coefficient of friction is increasing by increase load and velocity successively but when only sliding velocity is increasing the COF is decreasing. Presence of oxygen at wear track is also confirmed by EDS, causes to oxidation wear followed by three body abrasion with increasing load and velocity. Nature of wear mechanism cab be confirmed mild by study the less specific wear rate and also validated by the temperature of wear track.

\section{Acknowledgements}

The authors would like to thank the Department of Mechanical and Production Engineering of Delhi Technological University, Delhi-110042, India for the support of experimentation in the Laboratory. This work is also encouraged and guided by Dr.QasimMurtaza and Mr. Shailesh Mani Pandey.

\section{References-}

[1] Tung SC, Huang Y. Modeling of abrasive wear in a piston ring and enginecylinder bore systemtribology. Transactions 2004; 47:17-22.

[2] HanbeyHazar. Characterization of MoN coatings for pistons in a diesel engine: Materials and Design 31 (2010) 624-627.

[3] Andersson P, Tamminen J, Sandstrom CE. Piston ring tribology. VTT Res Notes2002;2178:1105. 
[4] CengizOner, HanbeyHazar, Mustafa Nursoy Surface properties of CrN coated engine cylinders Materials and Design 30 (2009) 914-920.

[5] Da-Yung Wang, Ko-Wei Weng, Surf. Coat.Technol. 137 (2001) 31.

[6] A.P. Ehiasarian, W.-D. Münz, L. Hultman, et al., Surf. Coat.Technol. 141 (2001) 227.

[7] Eun Young Choi, Myung Chang Kang, Dong Hee Kwon, J. Mater. Process. Technol. 187-188 (2007) 566.

[8] T. Elangovan, P. Kuppusami, R. Thirumurugesan, et al., Mater. Sci. Technol. B 167 (2010) 17.

[9] Xu. Junhua, Hiroyuki Umehara, Isao Kojima, Appl. Surf. Sci. 201 (2002) 208.

[10] P.Z. Shi , J. Wang , C.X. Tian, Z.G. Li , G.D. Zhang, D.J. Fu , B. Yang Structure, mechanical and tribological properties of $\mathrm{CrN}$ thick coatings deposited by circular combined tubular arc ion plating Surface \& Coatings Technology 228 (2013) S534-S537

[11] Friedrich C, Berg G, Bras EZ, Rick F, Holland J. PVD Crx N coatings for tribology application on piston rings. Surf Coat Technoly 1997;97:661-8.

[12] Kris De Moerlooze, Farid Al-Bender, Hendrik Van Brussel An experimental study of ball-onflat wear on a newly developed rotational tribometer Wear 271 (2011) 1005-1016.

[13] K. Holmberg, A. Matthews, Coatings Tribology, A Concept, Critical Aspects and Further Directions, ICMCTF, San Diego, 1994

[14] J.A. Picas , A. Forn, G. Matthaus HVOF coatings as an alternative to hard chrome for pistons and valves Wear 261 (2006) 477-484

[15] Ko-Wei Weng, Tai-Nan Lin, Da-Yung Wang, Tribological property enhancement of $\mathrm{CrN}$ films by metal vapor vacuum arc implantation of Vanadium and Carbon ions Thin Solid Films 516 (2008) 1012-1019

[16] M.B. Karamıs, K. Yıldızlı, H. C, akırer, Wear behaviour of Al-Mo-Ni composite coating at elevated temperature Wear 258 (2005) 744-751

[17] M Singh, D.P Mondal, O.P Modi, A.K Jha, Two-body abrasive wear behaviour of aluminium alloy-sillimanite particle reinforced composite, Wear, Volume 253, Issues 3-4, August 2002, Pages 357-368, ISSN 0043-1648.

[18] E. Martınez, U. Wiklund, J. Esteve, F. Montalà, L.L. Carreras Tribological performance of TiN supported molybdenum and tantalum carbide coatings in abrasion and sliding contac,t Wear 253 (2002) 1182-1187. 
[19] W.Y.H. Liew, Sebastian Dayou, Mohd. Azlan Bin Ismail1, Nancy J. Siambun1 and JedolDayou, Dry Sliding Behaviour of AlCrN and TiN Coatings Advanced Materials Research Vol. 576 (2012) pp 559-564doi:10.4028/www.scientific.net/AMR.576.559

[20] J.H. Ouyang, S. Sasaki, Tribo-oxidation of cathodic arc ion-plated (V, Ti) N coatings sliding against a steel ball under both unlubricated and boundary-lubricated conditions Surface \& Coatings Technology 187 (2004) 343-357

[21] A. Babilius, P. Ambroza. Effect of Temperature and Sliding Speed on the Adhesive Wear ISSN 1392-1320 MATERIALS SCIENCE (MEDŽIAGOTYRA). Vol. 9, No. 4. 2003

[22] Kim, S.J., Kim, K.K. Effects of Temperature and Contact Stress on the Sliding Wear of Nibase Deloro 50 Hardfacing Alloy Journal of Nuclear Materials 288 2001: pp. 163 - 169.

[23]K.V.Arun, C.S Venkatesha, Experimental investigations on fracture toughness and transition temperature in hard chrome coated structural materials Journal of material processing and technology Volume-207, Issues2-3,16 October 2008,Pages336-342.

[24]Kim, S.J., Kim, K.K. Effects of Temperature and Contact Stress on the Sliding Wear of NibaseDeloro 50 Hardfacing Alloy Journal of Nuclear Materials 288 2001: pp. 163 - 169

[25] A. Babilius, P. Ambroza Effect of Temperature and Sliding Speed on the Adhesive Wear ISSN 1392-1320 MATERIALS SCIENCE (MEDŽIAGOTYRA). Vol. 9, No. 4. 2003

[26] Zhiqiang Liu, Meng Hua, Wear transitions and mechanisms in lubricated sliding of a molybdenum coating, Tribology International, Volume 32, Issue 9, September 1999, Pages 499506, ISSN 0301-679X, http://dx.doi.org/10.1016/S0301-679X(99)00079-1.

[27] J. Lanigan, H. Zhao, A. Morina, A. Neville, Tribochemistry of silicon and oxygen doped, hydrogenated Diamond-like Carbon in fully-formulated oil against low additive oil, Tribology International, Volume 82, Part B, February 2015, Pages 431-442, ISSN 0301-679X, http://dx.doi.org/10.1016/j.triboint.2014.03.019 